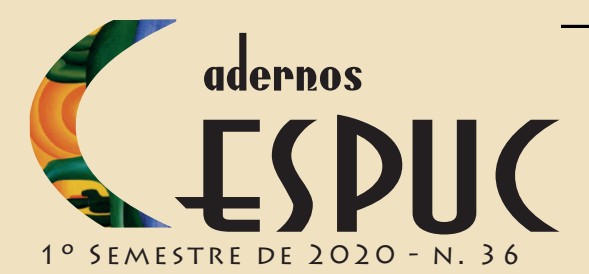

\title{
PARA ALÉM DA MOLDURA COR-DE-ROSA: DISPUTAS ENUNCIATIVAS NA COMPOSIÇÃO DE QUARENTA DIAS, DE MARIA VALÉRIA REZENDE
}

\author{
Vinícius Lourenço Linhares*
}

\begin{abstract}
Resumo
O intuito deste ensaio é mostrar como o processamento narrativo proposto por Maria Valéria Rezende, na composição do romance Quarenta dias, pode ser tomado como um operador de leitura, de caráter paradoxal, responsável por encenar uma territorialidade social marcada pelo aplainamento das relações estabelecidas entre os sujeitos ficcionais do/ no romance ao mesmo tempo em que se tensionam e se expõem contradições desse aplainamento.

Palavras-chave: Aplainamento de relações. Enunciação. Literatura. Território.
\end{abstract}

\section{BEYOND THE PINK FRAME: ENUNCIATIVE DISPUTES IN THE COMPOSITION OF QUARENTA DIAS, BY MARIA VALÉRIA REZENDE}

Abstract

The purpose of this paper is to show how the narrative processing proposed by Maria Valéria Rezende in the composition of the novel Quarenta dias can be taken as a paradoxical reading operator, responsible for staging a social territoriality marked by the flattening of relationships established between the fictional subjects of/in the novel at the same time that contradictions of this flattening are tensioned and exposed.

Keywords: Flattening relationships. Enunciation. Literature. Territory.

Recebido em 22/05/2020

Aceito em 14/07/2020

"Docente no Instituto Federal de Minas Gerais (IFMG). Doutorando e mestre em Literaturas de Língua Portuguesa pelo Programa de Pós-graduação em Letras da PUC Minas. Bolsista da CAPES II. https://orcid.org/0000-0002-3849-8217. 
Em Quarenta dias, romance de Maria Valéria Rezende, a estratégia enunciativa ${ }^{1}$ criada pela autora para armar seu texto convida a distintos caminhos de leitura. Opto por tomar como premissa a afirmação de que, ao construir uma narradora encenada como escritora da própria história, que interpela uma enunciatária que não a ouve e nem lhe responde, a autora cria um processamento narrativo marcado pelo esvaziamento da relação EU/TU. Esse esvaziamento se configura por um tipo de interlocução em que uma das partes envolvidas tem o seu discurso transformado em ruído, em uma fala sem contagem válida, num dado contexto. Esse expediente, por sua vez, pode ser aproximado da discussão realizada por Jaques Rancière ao sustentar a tese de que a política é uma atividade marcada pelo desentendimento e deslocamento de corpos. Diz o autor:

A atividade política é a que desloca um corpo do lugar que lhe era designado ou muda a destinação de um lugar; ela faz ver o que não cabia ser visto, faz ouvir um discurso ali onde só tinha lugar o ruído, faz ouvir como discurso o que só era ouvido como ruído. (RANCIÈRE, 2018, p. 43).

Levando em conta, pois, a atividade política nos termos propostos por Rancière (2018) é que se faz necessário, inicialmente, mostrar como se dá o processo enunciativo de Quarenta dias. Quem fala no romance, ou melhor, quem escreve é Alice. Uma mulher que, por volta de sessenta anos, coagida pela filha, Norinha, muda-se de João Pessoa, Paraíba, para Porto Alegre, Rio Grande do Sul para que ali estivesse a postos caso a filha, já com 35 anos, engravidasse e pudesse contar com a mãe para a função de uma avó/babá. Devido a um desentendimento com a filha e o marido desta, Umberto, por causa de uma viagem acadêmica para a Europa, que provocaria nova separação entre eles, Alice se afasta de ambos e passa quarenta dias andando pelas ruas de Porto Alegre.

Ao regressar dessa quarentena, ela se propõe a relatar o que viveu em um caderno velho que é tomado como diário. Na capa desse caderno, Alice depara a imagem da boneca Barbie e, ironicamente, passa a descrever sua quarentena tomando a boneca como interlocutora. Essa interlocução, por sua vez, é o mote estruturador do romance, responsável por distintas relações que se vão estabelecendo e sendo desdobradas entre os sujeitos ficcionais, enunciadores/ enunciatários, construídos no/pelo romance.

Interessa, pois, a este ensaio, ${ }^{2}$ levando em conta o referido processamento narrativo, tomado como estratégia central na composição do romance, mostrar como tal processamento pode ser considerado como um operador de leitura que exibe o caráter paradoxal da narrativa,

\footnotetext{
${ }^{1}$ Faço referência ao quadro teórico da enunciação, conforme estudos de Benveniste (1989; 1995), Bakhtin (2010) e Bakhtin/Volochínov (2009).

${ }^{2}$ Este trabalho faz parte de minha tese de doutoramento, sob orientação da professora Dra. Ivete Walty, ainda em curso, que se desenvolve perseguindo o seguinte objetivo geral: investigar a encenação da escrita em/de Quarenta dias e Carta à rainha louca, ambos de Maria Valéria Rezende, considerando possíveis (inter)relações dessa escrita encenada com o processo enunciativo de cada romance. O desenvolvimento da tese já vem rendendo alguns frutos, alguns dos quais já publicados, em forma de artigo, em outros periódicos. As discussões deste ensaio são desdobramentos do artigo "Brasil: duas vozes, duas medidas", publicado na revista Via Atlântica, periódico semestral do Programa de Pós-Graduação de Estudos Comparados de Literaturas de Língua Portuguesa da Universidade de São Paulo.
} 
encenando uma territorialidade social marcada pelo aplainamento das relações estabelecidas entre os sujeitos ficcionais no romance, ao mesmo tempo em que tensiona essas relações, expondo suas contradições.

No romance, a boneca Barbie pode ser compreendida como um parâmetro que metonimiza uma ordem estética, política, econômica, social e cultural traçada como valor hegemônico, de modo a invisibilizar quaisquer outras existências que se afastam desse parâmetro e, por isso, são consideradas falsificações, de menor qualidade e valor, não legitimadas. Para alcançar esse objetivo, focalizo especificamente cenas em que ocorrem diálogos estabelecidos entre Alice e sua prima Elizete, recorrentes no romance, tomando tais diálogos como interlocuções em que o já referido processamento narrativo é potencializado pela autora de modo a encenar e expor o esvaziamento da relação EU/TU e seus distintos desdobramentos, conforme já sinalizado.

Um desses desdobramentos liga-se à configuração de territórios, conceito aqui retomado da Geografia. Conforme aponta o geógrafo Marcelo Lopes de Souza, não sem muita polêmica, território é um conceito fundamentalmente caracterizado como a expressão espacial fruto de relações de poder (Cf. Souza, 2009, p.66). Enquadrando o conceito de território sob essa perspectiva, Souza (2009) prossegue sua exposição dizendo que nas relações de poder estão organicamente implicados aspectos políticos, culturais, econômicos e materiais. Sustentando uma discussão cujo paradigma se orienta numa perspectiva relacional e dinâmica, afirma que um território se forja na interação de agentes e um determinado substrato material e, por isso, torna-se uma expressão espacial do poder, entendido, este, como uma face, entre outras, da dimensão das relações sociais. ${ }^{3}$

Seguindo esse fio, portanto, nos diálogos que trago para a análise, é possível perceber como se configura um jogo territorial em que o Nordeste geográfico brasileiro, considerando a cidade de João Pessoa, é representado em relação à encenação do Sul geográfico, representado pela cidade de Porto Alegre. Cabe, portanto, perceber os efeitos de sentidos decorrentes desse jogo territorial no/pelo romance que vai se configurando numa dinâmica de aproximação e distanciamento. E o elemento textual, no recorte que realizei, é marcado pelo jogo enunciativo que se constrói em torno da imagem da "moldura cor-de-rosa", que delimita/demarca a perspectiva da boneca Barbie contraposta à perspectiva da narradora Alice, que questiona tal moldura, expandindo-a.

\section{Barbie: um recurso mentiroso e cheio de falsificações}

Alice e Barbie $^{4}$ são construídas como enunciadoras/enunciatárias postas em um jogo interlocutivo que jamais parece se realizar. Não sem razão tal jogo torna-se uma interlocução

\footnotetext{
${ }^{3} \mathrm{O}$ detalhamento da discussão feita por Marcelo Lopes de Souza encontra-se referenciado na bibliografia deste texto. Não há um consenso envolvendo a discussão do conceito de território no âmbito da Geografia. Retoma-se o conceito aqui, a partir de Souza (2009), não para discuti-lo, mas para aproximá-lo da leitura ora apresentada.

${ }^{4}$ Sobre a boneca Barbie, vale a lembrança de que esta se constitui em um dos grandes ícones culturais dos Estados Unidos. Desde sua criação, em 1959, a boneca circula por diversas mídias, numa ampla e capilarizada rede que interliga o cinema, a TV, brinquedos, jogos digitais, show business (mundo do espetáculo) e até produtos de higiene pessoal. Como estratégia composicional de Maria Valéria Rezende, a referida boneca é tomada como um artifício narrativo, motivo pelo qual seu caráter artificial diz respeito tanto à estratégia de composição, quanto ao caráter "falsificado" da narrativa totalizante que ela expressa na/pela boca, sobretudo de Elizete e Norinha. A primeira prima e a segunda filha de Alice.
} 


\section{Vimícius Lourenso Limhares}

1 OSEMESTRE DE $2020-$ N. 36

esvaziada, haja vista que, ao escrever em um caderno que contém a "Barbie na capa de moldura cor-de-rosa" (REZENDE, 2014, p. 7), delineia-se um gesto de escrita que busca ultrapassar e rasurar tal moldura. Esta, no contexto romanesco, afigura-se como um limite territorial traçado pela boneca Barbie, constituindo-se num valor de limitação, enquadramento, demarcação, entre outros valores, conforme se pode depreender pela imagem que a própria palavra moldura evoca.

Na tentativa de questionar essa moldura é que Alice toma o caderno e nele escreve, construindo-se como uma enunciadora em primeira pessoa que interpela a boneca como uma suposta confidente: "você é só um recurso mentiroso pra eu me sentir em comunicação com alguém” (REZENDE, 2014, p.123). Não apenas o recurso é mentiroso, mas a própria boneca e a ordem hegemônica que ela representa são igualmente "mentirosos", é o que parece insinuar a voz autoral no recorrente exercício de mostrar os bastidores do fazer romanesco. A partir dessa dinâmica, Alice vai "alargando" a referida moldura e alçando a sua voz à condição de enunciação qualificada: "Nem tenho vontade de jantar ainda, Barbie, agora quem fala sou eu e você fica muda aí, ouvindo.” (REZENDE, 2014, p. 104).

Não faltam momentos na narrativa em que Maria Valéria Rezende, num gesto de autodesnudamento, lembra ao leitor do fingimento que é a interlocução entre Alice e a boneca Barbie, ao mesmo tempo em que essa interlocução, fingida, frise-se, é realizada: "Chega de escrever qualquer coisa, ainda mais que você não dá a mínima pro que eu estou dizendo. Você só sabe inglês, não é?, ou nem isso? 'Good night, Barbie'." (REZENDE, 2014, p.56), ou, quando Alice suspende a escrita de suas lembranças, e escreve "Chega por hoje, Barbie. O resto que vem é pesado que só! Vou botar você pra dormir, que não quero que você se esgote antes de eu ter dito tudo." (REZENDE, 2014, p.77).

Na manutenção da interlocução envolvendo Alice e Barbie ao longo de toda a narrativa expõem-se tanto o caráter fingido da interlocução, quanto o caráter "plástico"/ "mentiroso" da própria boneca, conforme exposto nas passagens acima e acentuado na cena reproduzida abaixo na qual Alice se encontra em uma loja de quinquilharias de 1,99, em Porto Alegre:

Enveredei pelos corredores daquele espaço enorme de prateleiras cheias de tralha chinesa, coreana, paraguaia, ou "made in" qualquer fundo de quintal ou barracão de exploração de pobres bolivianos, frascos e potes de plástico dos mais variados formatos [...] inutilidades revestidas desse seu cor-de-rosa berrante, Barbie, [...] todas as inutilidades e mínimas utilidades baratas, pilhas de caixas de suas falsificações, Barbie, se é que há Barbies que não sejam falsificações. Nada pessoal, amiga, 'sorry', não fique chateada, mas você há de convir... Deixe pra lá (REZENDE, 2014 p.168).

A descrição operada na cena, ironicamente, além de deslocar a boneca de seu pretenso lugar de narrativa oficial/original, delineia um mapa de consumo baseado em "inutilidades", ao fazer menção ao conhecido "made in" (feito/produzido em), em língua inglesa, que marca o trânsito de uma produção que se dá em escala global e cuja originalidade mostra-se como um engodo que se vale da mão de obra de sujeitos pobres e explorados na produção de inutilidades, dentre as quais afiguram-se as pilhas de falsificações da boneca Barbie. 
Observe-se, portanto, que nesse jogo de se autoevidenciar como ficção, o romance busca desmascarar a narrativa da boneca, que, na economia da obra, mostra-se como uma narrativa oficial, hegemônica. Busca, ainda, colocar a nu distintas determinações envolvidas na produção material e, principalmente, simbólica, da boneca Barbie. Ao interpelar a boneca, portanto, Alice interpela o poder hegemonicamente instituído, uma vez que a boneca assume o papel de representante de um "padrão oficial" que mensura diversos aspectos tratados no romance.

Essa indagação sobre a boneca saber uma única língua - "você só sabe inglês, não é?" - abre o romance a uma outra assimetria de caráter territorial: a do norte dito global e a do sul dito local numa dinâmica que faz modular ecos imperialistas ("made in" é um exemplo) na interpelação que Alice faz à Barbie nas diversas vezes que expressões de língua inglesa são escritas e ironizadas por Alice. Tais ecos, parece-me, considerados numa dinâmica social de ordem pretensamente global (globalizante?), podem ser relacionados ao conceito de linhas abissais proposto pelo sociólogo português Boaventura de Souza Santos:

as linhas cartográficas 'abissais' que demarcavam o Velho e o Novo Mundo na era colonial subsistem estruturalmente no pensamento moderno ocidental e permanecem constitutivas das relações políticas e culturais excludentes mantidas no sistema mundial contemporâneo. (SANTOS, 2007, p. 3).

No romance, reitere-se, a boneca Barbie metonimiza uma ordem territorial, marcada pela ideia de originalidade, de narrativa oficial num jogo de poder cujas linhas territoriais são forjadas numa inter-relação que envolve os espaços geográficos de João Pessoa e Porto Alegre (Nordeste e Sul) e Brasil e Estado Unidos. Ao dirigir sua enunciação à boneca Barbie, representante desse território supostamente oficial/original, Alice também interpela outros enunciadores, como é o caso de sua prima Elizete, que encarna um "jeito Barbie de ser", diga-se assim, e, dessa forma, a enunciação dirigida à boneca, interpela, também, a prima, descortinando, por isso mesmo, algumas relações de poder que podem ser lidas nessa interlocução.

\section{Elizete e as revistas de celebridades}

Ainda na Paraíba, Alice é coagida, principalmente por sua prima Elizete, que se posiciona a favor de Norinha e passa a atuar para convencer Alice a se mudar para Porto Alegre. Em uma cena na qual Alice está em diálogo com a prima, lê-se o que se segue:

[...] fuxicando [Norinha] com parentes e amigos pelas minhas costas, conquistando cúmplices, o principal deles, a doida da Elizete, tão boa que é, mas sem nenhum juízo, deslumbrada com qualquer coisa que não esteja ao alcance dela, metendo-se toda semana em algum salão de beleza sem marcar hora, bem no sábado, quando está lotado e tem de esperar muito tempo, e só diz que está tarde demais e vai desistir quando já leu, de graça, todas aquelas revistas de celebridades internacionais, nacionais e municipais, sempre sonhando com o Sul: Tão mais desenvolvido, Alice, uma gente chique, bonita, sabida, você ia era se dar bem, lá! E eu ia the visitar sempre que pudesse. (REZENDE, 2014, p. 33). 


\section{Vinīius Lourenso Limhares}

10 SEMESTRE DE $2020-$ N. 36

A voz de Elizete ganha contorno de um olhar representante do senso comum dirigido a esse "Sul", em letra maiúscula, que se afigura como uma espécie de paraíso inalcançável, um sonho. Contrapondo-se a essa visão "deslumbrada", a voz de Alice é marcada pelo deboche comedido ao descrever o comportamento de Elizete que "se forma" na leitura de "todas aquelas revistas de celebridade internacionais, nacionais e municipais". Ao elencar as distintas revistas numa ordem decrescente Alice acaba por sugerir que seja no âmbito municipal, numa cidade da Paraíba, ou que seja no âmbito internacional, o que se lê nas referidas revistas é sempre a mesma narrativa, além de se poder perceber um cáustico tom da narradora relativamente às fontes de que dispõe a prima Elizete para formar e sustentar suas visões de mundo.

Ora, revistas de celebridades são sabidamente veículos cujo foco é vender um modelo familiar (supostamente bem sucedido), uma vida também supostamente marcada pelo sucesso, que, claro, deve vir regado com muita conquista material por mérito próprio... Isso para não dizer que essas revistas sustentam-se como espaços que primam pela circulação de opiniões e fulanizações que não se comprometem com a construção de conhecimentos relevantes e muito menos com posturas críticas, ao contrário, costumam reiteram o status quo.

Mais irônico do que as revistas de celebridades é o espaço em que a leitura feita por Elizete acontece: "em algum salão de beleza", no sábado, sem hora marcada. Um espaço no qual o foco dos cuidados e serviços prestados são de ordem estético-corporais de modo que ali se construa ou se monte uma imagem, geralmente, padronizada, a qual, por sua vez, é retroalimentada de diversas formas como exemplificam as referidas revistas cujas celebridades costumam ser "macaqueadas" em seus padrões estéticos e comportamentais. O que se observa, portanto, é que tais revistas passam a representar uma negação à alteridade, posto que apresentam modelos, valores e comportamentos que, mesmo não estando "ao alcance" de Elizete, constituem-se como uma fonte de (in)formação acessível para a prima. Assim como também são as imitações da boneca Barbie, vendidas por um preço mais barato para uma classe mais pobre, de modo que esse modelo de beleza, de riqueza e de consumo tornem-se, perversamente, claro, acessível a todos.

Nesse sentido, o Sul torna-se uma ficção, nos diz Alice, e a ordem vigente nas revistas de celebridades, lidas em salões de beleza, é arquitetada para "fazer a cabeça" de quem frequenta esses espaços como é o caso de Elizete que, ironicamente, apesar de parece não se reconhecer como um corpo retratado nas/pelas revistas que lê, exalta-as, o que se prova quando, ao volver seu olhar de sonhadora para o Sul, diz: "Tão mais desenvolvido, Alice, uma gente chique, bonita, sabida, você ia era se dar bem, lá! E eu ia lhe visitar sempre que pudesse.” (REZENDE, 2014, p. 33).

Sapiência e beleza são atributos do Sul, possivelmente retratados nas referidas revistas que Elizete lê e Alice (re)lê, pela lente do deslocamento, questionando a visão "deslumbrada" da prima que, diz Alice, permanece "denunciando os defeitos da vida aqui nessa nossa Paraíba, Ainda tão atrasadinha!, louvando as maravilhas do Sul que eu estaria prestes a conquistar." (REZENDE, 2014, p. 34). O que aí se percebe é o fato de Elizete ser mostrada numa posição de alienação do próprio lugar que ocupa na relação com o lugar com o qual está sempre "sonhando". E sonhos, como costumam apresentarem-se, produzem imagens distorcidas à 
semelhança do que parece ser o olhar de Elizete para esse Sul inatingível, conforme escreve Alice. Em sua perambulação por Porto Alegre, ao tomar um ônibus, a narradora novamente evoca suas interlocuções com a prima:

Não me perguntou [o motorista] nada sobre o pagamento da passagem, ninguém reparava em mim, talvez efeito dos meus cabelos que teimo em deixar grisalhos apesar da incansável insistência da Elizete, Credo, Alice, que desleixo!, nem parece que você é uma mulher inteligente e estudada, acha certo parecer uma velha bem antes mesmo de entrar nos sessenta?, tá igualzinha a sua avó, se for por economia me diga que eu conheço salões ótimos e com precinho bem maneiro. Pra ela, Barbie, todas seríamos como você, que já tem a minha idade, não é?, e não mudou de cara esse tempo todo... (REZENDE, 2014, p. 99).

É interessante notar como Alice aproxima Elizete da boneca Barbie, haja vista os valores cultivados pela prima - juventude eternizada, cuidados ligados a uma estética específica, a comportamentos e a valores também pré-determinados. Os cabelos grisalhos de Alice não são bem vindos numa ordem regida pelo "padrão Barbie" e são, por isso, sinais de desleixo. Novamente Alice tensiona os discursos hegemônicos, postos na boca de Elizete, que "impõem" a ela, Alice, um determinado modo de aparecer na cena pública, uma cena cujo ordenamento não acolhe a velhice e exatamente por isso Alice enuncia sua (in)visibilidade: "ninguém reparava em mim". E, novamente, surge o "salão" sugerido por Elizete: um espaço pronto para transformar Alice em um corpo passível de ser reparado e contabilizado e, por isso, a insistência da prima, que tão logo Alice disse que iria se mudar para Porto Alegre,

[...] assumiu o comando, certamente teleguiada por Norinha, começando por botar etiquetas com preços em tudo o que havia dentro do meu apartamento, separar as minhas roupas que, segundo ela, já estavam indecentes, Aqui vai que você use esses trapos, mas lá no Sul, de jeito nenhum! Tinha coisa, quase tudo, que nem pra brechó de pobre prestava, na sua abalizada opinião. Aos meus protestos ela atacava de perita: Pode deixar que de moda entendo eu, vejo todas as revistas, suas roupas são do século passado! (REZENDE, 2014, p. 37).

Novamente as revistas aparecem como fonte de (in)formação de Elizete, podendo ser lidas como metonímia de uma mídia hegemônica, espraiada em diversos meios de publicação e difusão: televisivo, radiofônico ou nas diversas formas e plataformas que a web proporciona. Essas revistas, na cena em questão, mostram-se como as vozes autorizadas e competentes ${ }^{5}$ por ditar e "abalizar" o que é e o que não é moda. Tais vozes, ao que parecem, são apenas incorporadas por Elizete sem que esta as ponha à prova, questionando-as. Tarefa que, por outro lado, compete à Alice ao ironizar a "abalizada opinião" da prima que, incisivamente, diz: "vejo todas as revistas", tornando-se, assim, a porta-voz dos discursos competentes ligados à moda aí veiculados.

Vale notar, ainda, o tensionamento de discursos que se faz entre as revistas de celebridades que circulam nos salões de beleza frequentados por Elizete, que consome e pratica a cultura aí veiculada, e o consumo cultural de Alice, marcado pela leitura de textos principalmente do domínio literário, expressados, sobretudo nos trechos de distintas obras literárias lidas pela

5 Segundo Chauí (2011), o discurso competente é "o discurso instituído, aquele no qual a linguagem sofre uma restrição que poderia ser assim resumida: não é qualquer um que pode dizer a qualquer outro qualquer coisa em qualquer lugar e em qualquer circunstância." (CHAUÍ, 2011, p. 19). 
personagem (e pela autora empírica, claro) que são tomados como epígrafes a cada retomada de escrita realizada por Alice no caderno da Barbie. A cena em que Alice, já em Porto Alegre, adentra "uma loja de quinquilharias de 1,99" (REZENDE, 2014, p.168) marca os dois tipos de consumos e a valoração que assumem no/pelo romance:

Surpresa!, após uma infindável exposição de porta-retratos de todo tamanho, me deparei com uma inacreditável mesa com pilhinhas de livros, vários exemplares de cada título, bordas amareladas mas as lombadas jamais dobradas, fundo de estoque de uma livraria falida?, de tudo que eu gostaria de ler e, de certo por isso mesmo, não vendia, bem que a Elizete sempre me disse que olhar minha estante dava desânimo, Só tem livro chato!, ao preço de 1,99, aliás, praticamente a única coisa na loja que só custava mesmo 1,99. (REZENDE, 2014, p. 168169).

Nesse percurso pela "loja de quinquilharias de 1,99", a descrição que Alice faz da disposição das mercadorias aí expostas (re)vela também um de seus lugares enunciativos no romance: o lugar de leitora de livros circunscritos a determinados nichos - literários, artes, humanidades, teoria literária, etc. - o que acaba reforçando seu ethos como professora, revelando, ainda, a identidade de professora e educadora popular da própria Maria Valéria Rezende. Cabe destacar, inicialmente, que efeitos de sentidos a fala de Elizete, reportada por Alice, assume no romance: ao valorar a estante de Alice como desanimadora, na qual "só tem livro chato!", Elizete é mostrada como uma personagem cujo consumo cultural é marcado por uma mesma toada e, por isso mesmo, é uma personagem incapaz de perceber outras perspectivas além daquela trazida pelas revistas de celebridades, que parecem padronizar além da moda de vestuário, um modo de vida.

Construída como alguém com uma perspectiva limitada, que se mostra única, circunscrita à "moldura cor-de-rosa" e referendada pelas revistas de celebridades, Elizete é incapaz de suspeitar que talvez os livros na estante de Alice possam oferecer-lhe outras perspectivas. Daí a sua fala: "só tem livro chato". Menor ainda é a capacidade da personagem em colocar sob suspeita as próprias revistas e, por isso também, a ironia de Alice que, em outro momento, diz, referindo-se à Elizete: "fiquei num limbo [...] propositalmente emburrada pra ver se ela desistia de sua tagarelice desenfreada sobre as belezas do Sul que ela nunca tinha visto [...] (REZENDE, 2014, p. 38, grifo acrescentado). O contrassenso na cena reforça o lugar de senso comum ocupado por Elizete, que é capaz de qualificar os livros que talvez não tenha lido como "chatos" e, ainda, tagarelar sobre "as belezas do Sul" sem, no entanto, conhecer essas supostas belezas. Daí que, numa das interpelações à Barbie, Alice parece, também, interpelar Elizete: "Você leu 'Alice no país das maravilhas', Barbie?; leu nada! Você deve ser analfabeta de pai e mãe, não entende essas coisas que eu digo. Deixa pra lá, eu estou dizendo pra mim, pra ninguém" (REZENDE, 2014, p. 48).

O deslumbramento da prima com o que se mostra fora de seu alcance coloca em tensão espaços enunciativos e geográficos dos quais se enunciam tanto Elizete como Alice, numa dinâmica de (não) pertencimento a esses espaços, o que pode ser percebido quando Elizete diz para Alice: "Aqui vai que você use esses trapos, mas lá no Sul, de jeito nenhum?" Ora, apesar de pertencer ao "aqui" de onde enuncia, Elizete não somente pouco se identifica com esse 
espaço, como também o considera o lugar em que usar "esses trapos” mostra-se autorizado. Já o outro espaço, o "lá no Sul", na visão "deslumbrada" de Elizete, contrapõe-se ao seu "aqui" de (não) pertencimento a João Pessoa. Constrói-se nessa contraposição - aqui/lá - um efeito irônico quando, pelo olhar de Elizete, os "trapos" de Alice podem ser deslocados para predicar não apenas as roupas, mas principalmente, o próprio "aqui" - João Pessoa - de onde se originam as duas personagens. A ironia, está claro, dá-se sempre no olhar de Alice que, ao ter cruzada a sua perspectiva com a de Elizete, confrontando-as, tensiona e desloca a visão deslumbrada que a prima tem do Sul.

Exatamente por conta desse movimento de deslocamento, que esse (não) reconhecimento do próprio espaço, tanto o geográfico, quanto, principalmente o de enunciação de Elizete é, por outro lado, reconhecido e valorizado por Alice, haja vista que são os "trapos" de histórias que ela ouve na sua perambulação pelas ruas e margens de Porto Alegre que serão tomados como matéria digna de valor a ser enunciada na interlocução de Alice com distintos enunciadores, em Porto Alegre, como se lê a seguir:

[...] boca desdentada [...] moradora de rua, pedinte, arrastando aquele carrinho enferrujado afanado da porta de um supermercado qualquer ou recuperado de ferro-velho, empanturrado de sobejos do consumismo dos outros, de todo tipo, equilibrando milagrosamente uma montanha maior que ela de latinhas de refrigerantes e garrafas pet amassadas, folhas de papelão, montes de trapos escapando pelas aberturas da grade do carrinho, um vulto a mais dos muitos semelhantes que eu já tinha entrevisto por ali, como coisas das ruas, sem lhes conceder mais atenção do que a um banco de praça, uma lixeira, um orelhão inútil. A rua é cheia de coisas sem muita serventia, Barbie, do mesmo jeitinho que os quartos das meninas de hoje que você costuma frequentar, só o preço é que difere. (REZENDE, 2014, p.196).

As maravilhas do Sul que, segundo Elizete, Alice estaria prestes a conhecer são completamente implodidas na descrição que Alice realiza de seu encontro com uma moradora de rua de Porto Alegre. Na escrita de suas lembranças postulando a boneca Barbie como sua enunciatária fingida, Alice acaba "levando" a boneca para fora dos espaços em que habitualmente ela circularia, fazendo-a circular pelos espaços onde ela, Alice, transitou. Expande-se, assim, a "capa de moldura cor-de-rosa" (REZENDE, 2014, p.7) que condiciona o olhar e as vivências da boneca. No caso de Elizete, que apresenta um comportamento "de Barbie”, Alice, embora interpele a boneca, parece, também, dizer para a prima: "E vamos lá, Barbie, prefiro você que certamente não vê nada, com esses seus olhos de tinta e papel, tenha paciência comigo" (REZENDE, 2014, p. 49).

Semelhantemente à boneca que "certamente não vê nada", Elizete não seria capaz de ver nada que extrapolasse a narrativa oficial representada pela boneca Barbie e que, por isso mesmo, nada que extrapole o que ela vê/lê em todas "as revistas de celebridades", conforme já analisado. Frise-se, ainda, como o gesto metanarrativo de Maria Valéria Rezende potencializa não apenas o estatuto de ficcionalidade do romance, mas também o caráter "falsificado" e totalizador da ordem que a boneca Barbie representa.

Na cena reproduzida acima, Alice mostra à Barbie/Elizete algumas "belezas" do Sul: tomando a rua como espaço de encontros e interlocuções, as imagens evocadas na descrição 


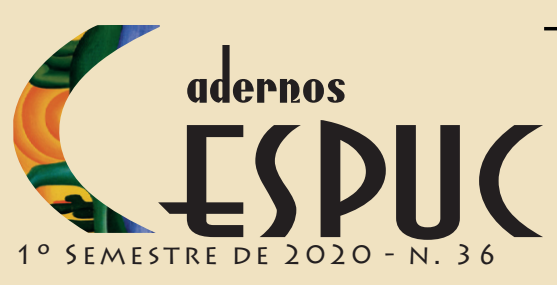

\section{Vinícius Lourenso Limhares}

desse espaço, expõem sua profunda contradição e desigualdade (Cf. Souza, 2004). Trata-se de uma descrição que parece se organizar numa forma de colagem, de modo a tornar indistinta a "moradora de rua" dos diversos materiais/detritos que ela recolhe e busca acondicionar no "carrinho enferrujado" que arrasta. As imagens de "boca desdentada" e "sobejos de consumismo dos outros" parecem ser os dois pólos que potencializam a contradição entre o excesso e a falta ou, nos termos em que temos insistido, potencializam o esvaziamento da relação eu/tu, expondo sua lógica de assimetria.

Outros elementos "colados" na composição da cena - "as latinhas de refrigerantes e garrafas pet amassadas, folhas de papelão, montes de trapos escapando pelas aberturas da grade do carrinho" (grifos acrescentados) - parecem performar a contaminação de um espaço em outro, de modo que seja possível ler, metonimicamente, a contradição desses elementos, "montes de trapos", como os restos que embora sejam descartados por aqueles que podem consumir sobejamente (pertencentes ao espaço oficial, da fartura e abundância), são "mastigados/reciclados" por uma "boca desdentada" e depurados na/pela escrita do romance. Frise-se que a própria narrativa vem de uma "boca desdentada" na medida em que tal boca, que se constitui como a voz da narradora/da autora não é reconhecida pela ordem hegemônica de que (não) participa e para a qual se enuncia.

As duas ordens aí encenadas - o sobejo e a míngua - desencadeadas pelo encontro de Alice com a moradora de rua, permanecem numa tensão que se mantém latente na imagem do equilíbrio milagroso de trapos no carrinho empurrado pela moradora de rua. $\mathrm{O}$ mesmo carrinho, ainda, parece ser a tentativa de delimitar uma fronteira entre a "boca desdentada" e os "sobejos de consumismo dos outros", mas essa fronteira ameaça ser rompida, uma vez que "pelas aberturas da grade do carrinho" os detritos e restos recolhidos pela moradora de rua escapam, contaminando a cidade e expondo-lhe seu avesso.

O exercício de escrita feito por Alice, nesse sentido, mostra-se como uma transposição das referidas fronteiras, posto que tal exercício faz aparecer aos "olhos de tinta e papel" da boneca outros sujeitos ficcionais que, embora componham a geografia de Porto Alegre, circulando e morando nas ruas da cidade e em outros espaços periféricos, são vistos como "um vulto" "como coisas das ruas" "um banco de praça, uma lixeira, um orelhão inútil" (REZENDE, 2014, p.196, grifos acrescentados).

Deslocando, portanto, a boneca para o espaço da rua e, claro, o olhar deslumbrado da prima Elizete, Alice expõe, ironicamente, “as belezas do Sul que ela [Elizete] nunca tinha visto”. Como consequência disso, o romance acaba se mostrando como uma enunciação cujas fronteiras territoriais, marcadas no contraponto geográfico envolvendo a Paraíba e Porto Alegre, vão sendo questionadas e rasuradas por meio de um processamento narrativo que, ao encenar uma ordem social marcada pelo aplainamento de relações estabelecidas entre os sujeitos ficcionais do/no romance, evidencia, também, algumas contradições dessa ordem, extrapolando, por isso mesmo, a "moldura cor-de-rosa" traçada como limite pela boneca Barbie. 


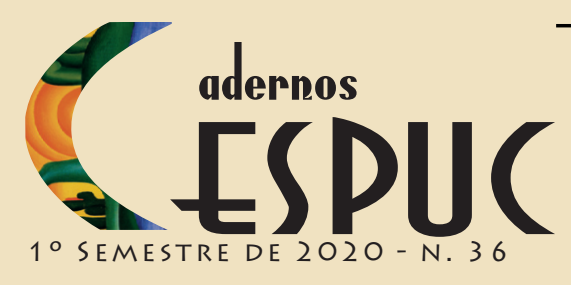

\section{Vimícius Lourenso Limhares}

\section{Referências}

BAKHTIN, Mikhail. Questões de Literatura e de Estética: a teoria do romance. 6.ed. Tradução de Aurora Fornoni Bernardini et al. São Paulo: Hucitec, 2010.

BAKHTIN, Mikhail;VOLOCHINOV. Marxismo e filosofia da linguagem. 13.ed. Tradução de Michel Lahud; Yara F. Vieira. São Paulo: Hucitec, 2009.

BENVENISTE, Émile. Problemas de Linguística Geral I. 4.ed. Tradução de Maria da Glória Novak; Maria Luísa Neri.Campinas (SP): Pontes, 1995.

BENVENISTE, Émile. Problemas de Linguística Geral II. 2.ed. Tradução de Eduardo Guimarães et al. Campinas (SP): Pontes, 1989.

CHAUÍ, Marilena. Cultura e democracia. O discurso competente e outras falas. São Paulo: Cortez, 2011.

LINHARES, Vinícius Lourenço. Brasil: duas vozes, duas medidas. Via Atlântica (USP), n. 35, p. 287-305, 2019. Disponível em: https://doi.org/10.11606/va.v0i35.155051. Acesso em: 31 mar. 2020.

RANCIÈRE, Jacques. O desentendimento: política e filosofia. Tradução de Ângela Leite Lopes. São Paulo: Editora 34, 2018.

REZENDE, Maria Valéria. Quarenta dias. Rio de Janeiro: Objetiva, 2014.

SANTOS, Boaventura de Souza. Para além do pensamento abissal: das linhas globais a uma ecologia de saberes. Revista Crítica de Ciências Sociais, v.78, 2007, p. 3-46. Disponível em: https://doi.org/10.4000/rccs.753. 